\title{
Instruction to Authors
}

Please read the updated instructions carefully and follow them strictly. Submissions not complying with these instructions will not be considered.

\section{Submission of contributions}

All submissions and correspondence should be addressed to the Secretary and Manager, The Journal of Obstetrics and Gynecology of India, Model Residency CHS, Ground Floor, 605 Bapurao Jagtap Marg, Jacob Circle, Mahalaxmi East, Mumbai - 400011. All articles submitted for publication are meant exclusively for publication in this Journal and must be accompanied by the following warranty signed by all the authors.

The undersigned author / authors hereby declare that the article is original, neither the article nor a part of it is under consideration for publication anywhere else and has not been previously published anywhere. We have declared all vested interests. We have meticulously followed the instructions. The article, if published, shall be the property of the Journal and we surrender all rights to the Editor. We agree to provide the latest follow-up of cases prior to the publication of case reports when requested. The Journal office accepts only electronic paper submission on the website www.editorialmanager.com/jogi/ Authors must ensure that once the paper is submitted electronically, the same manuscript is not submitted in journal office by post or on the website to avoid duplication and in case of duplicate submission both submissions may stand cancelled.

\section{Conflicts of interest/Competing interests}

All authors of must disclose any and all conflicts of interest they may have with publication of the manuscript or an institution or product that is mentioned in the manuscript and/or is important to the outcome of the study presented. Authors should also disclose conflict of interest with products that compete with those mentioned in their manuscript.

\section{Copyright}

All articles published in this Journal become the property of the Journal and should not be published or reproduced in any form, in full or in part, without the written permission of the Editor.

\section{Copies of any permission(s)}

It is the responsibility of authors/contributors to obtain permissions for reproducing any copyrighted material. A copy of the permission obtained must accompany the manuscript. Copies of any and all published articles or other manuscripts in preparation of submitted elsewhere that are related to the manuscript must also accompany the manuscript. The material should be sent to the addresses given above. Any material received without such evidence will be assumed to originate from authors.

\section{Responsibility}

The contents of the articles and the views expressed therein are the sole responsibility of the authors, and the editorial board will not be held responsible for the same.

\section{Manuscripts}

(1) Manuscripts must be submitted in precise, unambiguous, concise and easy to read English.

(2) The number of authors should not exceed six.

(3) Type of article must be specified. 1. review article 2. original paper-obstetrics 3. original paper-gynecology 4. case report 5. letter to editor.

(4) Using automated page numbering function, number all pages consecutively in Arabic numerals at the top right side in the following order:

(a) Title of the article and Capsule

Capsule of one or two sentences giving the essence of the study.

Full names (beginning with underlined surname) and designations of all authors.

Institutions where the study was conducted and address (with PIN/Zip code) for correspondence along with mobile and telephone number, fax number and e-mail address and a list of 3 to 5 key words for indexing and retrieval. 
(b) Structured abstract

A structured abstract, limited to 150 words, is to be used for original articles only. The structured abstract is to contain the following major headings: Objectives, Methods, Results and Conclusions. The Objective reflects the purpose of the study or the hypothesis that is being tested. The Methods (Study Design) should include the setting for the study, the subjects, (number and type) studied, the treatment or intervention, and the tools of statistical analysis. The Results include the outcome of the study and statistical evaluation. The Conclusion states the significance of the results.

(c) Text

Not to exceed six foolscap typed sheets, or 2500 words. Use only standard abbreviations, symbols and acronyms that are universally accepted. Give full form of all abbreviations at their first citation in the text. Use only American spell check for English eg fetus instead of foetus. When using Microsoft word, click on tools select spelling and choose English(US).

\section{Text Formatting}

Manuscripts should be submitted in Word

- Use a normal, plain font (e.g., 10-point Times Roman) for text.

- Use italics for emphasis.

- Use the automatic page numbering function to number the pages.

- Do not use field functions.

- Use tab stops or other commands for indents, not the space bar.

- Use the table function, not spreadsheets, to make tables.

- Use the equation editor or MathType for equations.

- Save your file in docx format (Word 2007 or higher) or doc format (older Word versions).

- Word template (zip, $154 \mathrm{kB}$ ).

- Manuscripts with mathematical content can also be submitted in LaTeX.

- $\quad$ LaTeX macro package (zip, $182 \mathrm{kB}$ ).

- Headings.

- Please use no more than three levels of displayed headings.

Introduction - Give the aim of the study and justification for the study.

Methods - Use only generic names of drugs. For referring to less than 10 persons, objects, etc., spell out the number. For more than 10 use Arabic numerals. While comparing less than 10 with more than 10 use Arabic numerals for uniformity. Number starting the sentence should be spelled out, unless it involves a decimal point. Refer obstetric cases as women and not patients. Those in comparative studies should be referred to as subjects and controls. All the measurements must be in metric units and temperature in degree Celsius.

\section{Tables}

- Tables should be self-explanatory and should not duplicate textual material.

- The number of tables should not exceed five.

- Tables with more than 10 columns and 25 rows are not acceptable. Each column should have a heading.

- Do not use vertical rules.

- Number tables, in Arabic numerals, consecutively in the order of their first citation in the text and supply a brief title for each.

- Place explanatory matter in footnotes and not in the heading.

- Explain in footnotes all non-standard abbreviations that are used in each table.

- Obtain permission for all fully borrowed, adapted and modified tables and provide a credit line in the footnote.

- For footnotes use the following symbols, in this sequence: $*, \dagger, \ddagger, \S, \| \uparrow, * *, \dagger \dagger, \ddagger \ddagger$.

- Tables with their legends should be provided at the end of the text after the references. Each table must be typed double spaced, on a separate sheet of paper.

- The tables along with their number should be cited at the relevant place in the text.

\section{Figures and Photographs}

These should be serially numbered in Arabic numerals. Figures should be unmounted in black ink drawings of professional quality with clear lettering. They should have a legend. Matter given in a Table must not be repeated as a Figure. Black and white photographs should have a sharp contrast between black and white areas. They should be $8 \times 13 \mathrm{~cm}$ in size. If applicable a linear scale should be incorporated in the photograph or magnification stated. The word "Top" should be written in the appropriate place. A legend should be supplied for each photograph typed double spaced in consecutive order 
on a separate page, in the text file of the manuscript, and not in the figure. Costs of processing and printing of figures and photographs will have to be paid in advance by the author on acceptance of the paper. For the detailed instructions please refer to instructions online.

Study design: Selection and Description of Participants: Describe your selection of the observational or experimental participants (patients or laboratory animals, including controls) clearly including eligibility and exclusion criteria and a description of the source population. Technical information: identify the methods, apparatus (give the manufacturers name and address in parentheses) and procedures in sufficient detail to allow other workers to reproduce the results. Give references to established methods, including statistical methods (see below); provide references and brief descriptions for methods that have been published but are not well known; describe new or substantially modified methods, give reasons for using them, and evaluate their limitations. Identify precisely all drugs and chemicals used, including generic name(s), dose(s), and route(s) of administration.

Reports of randomized clinical trials should present information on all major study elements, including trials, present information on all major study elements, including the protocol, assignment of interventions (methods of randomization, concealment of allocation to treatment groups) and the method of masking (blinding) based on the CONSORT Statement (http://www.consortstatement.org).

\section{Reporting Guidelines for Specific Study Designs}

\begin{tabular}{|l|l|l|}
\hline Intiative & Type of Study & Source \\
\hline CONSORT & Randomized controlled trials & http://www.consort-statement.org \\
STARD & Study of diagnostic accuracy & http://www.consort-statement.org/stardstatement.htm \\
QUORUM & $\begin{array}{l}\text { Systematic reviews and Meta-analyses } \\
\text { Statement.org/Intiatives/MOOSE/ } \\
\text { moose.pdf }\end{array}$ & http:www.consort-statement.org/ \\
& $\begin{array}{l}\text { Observational studies in Epidemiology } \\
\text { STROBE }\end{array}$ & http:/www.strobe-statement.org \\
& $\begin{array}{l}\text { Meta-analyses of observational } \\
\text { MOOSE }\end{array}$ & $\begin{array}{l}\text { http://www.consort-statement.org/ } \\
\text { Intiatives/MOOSE/moose.pdf }\end{array}$ \\
& \multicolumn{2}{|l}{} \\
\hline
\end{tabular}

Statistics: Whenever possible quantify findings and present them with appropriate indicators of measurement error or uncertainty (such as confidence intervals). Authors should report losses to observation (such as, dropouts from a clinical trial). When data are summarized in the Results section, specify the statistical methods used to analyze them. Avoid nontechnical uses of technical terms in statistics, such as 'random' (which implies a randomizing device), 'normal, 'significant', 'correlations', and 'sample'. Define statistical terms, abbreviations, and most symbols. Specify the computer software used. Use upper italics (P 0.048). For all P values include the exact value and not less than 0.05 or 0.001 . Mean differences in continuous variables, proportions in categorical variables and relative risks including odds ratios and hazard ratios should be accompanied by their confidence intervals.

Results: Present your results in a logical sequence in the text, tables and illustrations, giving the main or most important findings first. Do not repeat in the text all the data in the tables or illustrations; emphasize or summarize only important observations. Extra or supplementary materials and technical detail can be placed in an appendix where it will be accessible but will not interrupt the flow of the text; alternatively, it can be published only in the electronic version of the journal. When data are summarized in the Results section, give numeric results not only as derivatives (for example, percentages) but also as the absolute numbers from which the derivatives were calculated, and specify the statistical methods used to analyze them. Restrict tables and figures to those needed to explain the argument of the paper and to assess its support. Use graphs as an alternative to tables with many entries; do not duplicate data in graphs and tables. Where scientifically appropriate, analyses of the data by variables such as age and sex should be included.

\section{Clinical Trial Registry}

All clinical trials, including the ongoing ones, must be registered with Clinical Trial Registry of India on www.ctri.in Ethics: When reporting studies on human beings, indicate whether the procedures followed were in accordance with the ethical standards of the responsible committee on human experimentation (institutional or reginal) and with the Helsinki Declaration of 1975, as revised in 2000 (available at http://www.wma.net/e/polocy/17-c_e.html). For prospective studies involving human participants, authors are expected to mention about approval (regional/national/institutional or independent Ethics Committee or Review Board), obtaining informed consent from adult research participants and obtaining assent for 
children aged over 7 years participating in the trial. The age beyond which assent would be required could vary as per regional and/or national guidelines. Ensure confidentiality of subjects by desisting from mentioning participants' names, initials or hospital numbers, especially in illustrative material. When reporting experiments on animals. Indicate whether the institution's or a national research council's guide for, or any national law on the care and use of laboratory animals was followed.

Evidence for approval by a local Ethics Committee (for both human as well as animal studies) must be supplied by the authors on demand. The ethical standards of experiments must be in accordance with the guidelines provided by the CPCSEA and World Medical Association Declaration of Helsinki on Ethical Principles for Medical Research involving Humans for studies involving experimental animals and human beings respectively). The journal will not consider any paper which is ethically unacceptable.

Discussion - Statements made should be supported by the data collected and/or literature references.

\section{Review articles}

It is expected that these articles would be written by individuals who have done substantial work on the subject or are considered experts in the field. A short summary of the work done by the contributors (s) in the field of review should accompany the manuscript.

The prescribed word count is up to 4000 words excluding tables, references and abstract. The manuscript may have about 30 references. The manuscript should have an unstructured abstract (150 words) representing an accurate summary of the article. The section titles would depend upon the topic reviewed.

\section{Case reports}

The manuscript should be of up to 500 words (excluding references and abstract) and should be supported with up to 2 references and one photograph. Case Reports could be authored by up to four authors. Only exclusive case reports of practical interest and a new message will be considered.

Letter to the Editor: These should be short and decisive observations. They should preferably be related to articles previously published in the Journal or views expressed in the journal. They should not be preliminary observations that need a later paper for validation. The letter could have up to 500 words and 2 references. It could be generally authored by not more than four authors.

\section{References}

i) The number of references must not exceed 15. Only recent (not more than 15 years old) references should be used. Do not give text books as references.

ii) References must be numbered consecutively in the sequential order in which they are mentioned in the text, tables and figures. They must be cited in the text, tables and figures as the number in square brackets, corresponding to reference in the reference list. For the sample of the referencing style refer to online instruction.

iii) Reference list must be set out in format used by the NLM (Vancouver style) in Index Medicus, giving authors' surnames and initials, title of the paper, abbreviation of the Journal, year, volume number, and first and last page numbers. Give surnames and initials of all the authors.

iv) Medical Journal abbreviations must be as used by Index Medicus.

v) Books-Text Books should not be used as references. Other books should be quoted as Authors (surnames followed by initials) of chapter / section, and its title, followed by Editors-(names followed by initials), title of the book, number of the edition, city of publication, name of the publisher, year of publication and number of the first and the last page referred to.

vi) Abstracts of papers presented at conferences should be cited only from the published proceedings strictly using the format of the surname of authors followed by initials, title of the paper, title of the abstract book, city of publication, name of the publisher, year of publication, and page numbers referred to.

vii) Unpublished work, work in preparation, and personal communications should only be mentioned in the text and not used as references. Personal communication must carry the date of the communication. However, work accepted for publication should be included in the reference list as 'In Press' giving the name of the Journal.

viii) 'Quoted by' references are not accepted.

ix) Responsibility: Authors are solely responsible for the accuracy of references.

x) Scanned copies of the title pages of all the Journal articles, and title page and its backside of the books quoted in reference list must accompany the manuscript.

\section{The Editorial Process}

A manuscript will be reviewed for possible publication with the understanding that it is being submitted to The Journal of Obstetrics and Gynecology of India alone at that point in time and has not been published anywhere, simultaneously submitted, or already accepted for publication elsewhere. The journal expects that authors would authorize one of them 
to correspond with the Journal for all matters related to the manuscript. All manuscripts received are duly acknowledged. On submission, editors review all submitted manuscripts initially for suitability for formal review. Manuscripts with insufficient originality, serious scientific or technical flaws, or lack of a significant message are rejected before proceeding for formal peer review. Manuscripts that are unlikely to be of interest of the Journal of Obstetrics and Gynecology of India readers are also liable to be rejected at this stage itself. Manuscripts that are found suitable for publication in The Journal of Obstetrics and Gynecology of India are sent to two or more expert reviewers. The Journal follows a double-blind review process, wherein the reviewers and authors are unaware of each other's identity. A blinded manuscript without any authors names and affiliations in the text or on the title page. Self-identifying citations and references in the article text should be avoided. A separate title page, containing title, all authors names, affiliations, and the contact information of the corresponding author. Any acknowledgements, disclosures, or funding information should also be included on this page. The comments and suggestions (acceptance/rejection/amendments in manuscript) received from reviewers are conveyed to the editor for further processing.

Manuscripts accepted for publication are copy edited for grammar, punctuation, print style and format.

Upon acceptance of your article you will receive a link to the special Author Query Application at Springer's web page where you can indicate whether you wish to order offprints. Once the Author Query Application has been completed, your article will be processed and you will receive the proofs.

\section{Copyright transfer}

Authors will be asked to transfer copyright of the article to the Society. This will ensure the widest possible protection and dissemination of information under copyright laws.

\section{Offprints}

Offprints can be ordered by the corresponding author.

\section{Proof reading}

The purpose of the proof when sent to author is to check for typesetting or conversion errors and the completeness and accuracy of the text, tables and figures. Substantial changes in content, e.g., new results, corrected values, title and authorship, are not allowed without the approval of the Editor. After online publication, further changes can only be made in the form of an Erratum, which will be hyperlinked to the article.

\section{Online First}

The article will be published online after receipt of the corrected proofs. This is the official first publication citable with the DOI. After release of the printed version, the paper can also be cited by issue and page numbers.

Manuscripts will not be returned or preserved.

Reprints can be ordered on payment by author after acceptance of the paper Protection of Patients' Rights to Privacy Identifying information should not be published in written descriptions, photographs, sonograms, CT scan etc., and pedigrees unless the information is essential for scientific purposes and the patient (or parent or guardian, wherever applicable) gives written informed consent for publication. Authors should remove patients' names from figures unless they have obtained written informed consent from the patients. When informed consent has been obtained, it should be indicated in the article and copy of the consent should be attached with the covering letter.

Please ensure compliance with the following check-list as an excel sheet online

- Warranty-Signature of all authors

- Designation and Institute of all authors, specify name, address and e-mail of corresponding author.

- Specify Type of paper, Number of tables, Number of figures, Number of references,

- Original article:

- Capsule-50 words

- Running title of upto five words

- Structured abstract-150 words

- Manuscript—up to 2500 words

- Key words-3 to 5 words

- Tables-not more than 5

- Figures with legends-8 $-13 \mathrm{~cm}$ in size

- Reference list: Up to 15 references in Vancouver style

- Case report \& letter to editor - 500 words without abstract with 2-3 references in Vancouver style, \& 3-5 key words

- Review article-4000 words, unstructured abstract of 150 words with up to 30 references in Vancouver style \& 3-5 keywords

- Accurate reference list with scanned copies of title pages of all references. 